\title{
Ralstonia solanacearum Type III Effector RipJ Triggers Bacterial Wilt Resistance in Solanum pimpinellifolium
}

\author{
Ankita Pandey, ${ }^{1}$ Hayoung Moon, ${ }^{1}$ Sera Choi, ${ }^{1}$ Hayeon Yoon, ${ }^{1}$ Maxim Prokchorchik,,${ }^{1,2}$, Jay Jayaraman, ${ }^{3}$ \\ Rajendran Sujeevan, ${ }^{4}$ Yu Mi Kang, ${ }^{5}$ Honour C. McCann, ${ }^{6,7}$ Cécile Segonzac, ${ }^{8,9,10}$ Chul Min Kim, ${ }^{5, \dagger}$ \\ Soon Ju Park, ${ }^{4, \dagger}$ and Kee Hoon Sohn ${ }^{1,11, \dagger}$ \\ ${ }^{1}$ Department of Life Sciences, Pohang University of Science and Technology, Pohang 37673, Republic of Korea \\ ${ }^{2}$ Institute of Crop Science and Resource Conservation (INRES), University of Bonn, Germany \\ ${ }^{3}$ New Zealand Institute for Plant \& Food Research Limited (PFR), Mt Albert Auckland 1025, New Zealand \\ ${ }^{4}$ Division of Biological Sciences and Research Institute for Basic Science, Wonkwang University, Iksan 54538, Republic of \\ Korea \\ ${ }^{5}$ Division of Horticulture Industry, Wonkwang University, Iksan 554438, Republic of Korea \\ ${ }^{6}$ Institute of Advanced Studies, Massey University, Auckland 0745, New Zealand \\ ${ }^{7}$ Max Planck Institute for Developmental Biology, Tübingen, Germany \\ ${ }^{8}$ Department of Plant Science, Plant Genome and Breeding Institute, Agricultural Life Science Research Institute, Seoul \\ National University, 08826, Seoul, Republic of Korea \\ ${ }^{9}$ Plant Immunity Research Center, Seoul National University, 08826, Seoul, Republic of Korea \\ ${ }^{10}$ Department of Agriculture, Forestry and Bioresources, Seoul National University, 08826, Seoul, Republic of Korea \\ ${ }^{11}$ School of Interdisciplinary Biosciences and Bioengineering, Pohang University of Science and Technology, Pohang 37673, \\ Republic of Korea
}

Accepted 26 March 2021.

Ralstonia solanacearum causes bacterial wilt disease in solanaceous crops. Identification of avirulence type III-secreted effectors recognized by specific disease resistance proteins in host plant species is an important step toward developing durable resistance in crops. In the present study, we show that $R$. solanacearum effector RipJ functions as an avirulence determinant in Solanum pimpinellifolium LA2093. In all, 10 candidate avirulence effectors were shortlisted based on the effector repertoire comparison between avirulent $\mathrm{Pe}_{-} 9$ and virulent Pe_1 strains. Infection assays with transgenic strain Pe_1 individually carrying a candidate avirulence effector from Pe_9 revealed that only RipJ elicits strong bacterial wilt resistance in $S$. pimpinellifolium LA2093. Furthermore, we identified that several RipJ natural variants do not induce bacterial wilt resistance in $S$. pimpinellifolium LA2093. RipJ

\begin{abstract}
${ }^{\dagger}$ Corresponding authors: C. M. Kim; chulmin21@wku.ac.kr, S. J. Park; sjpark75@wku.ac.kr, and K. H. Sohn; khsohn@ postech.ac.kr

Funding: Solanum lycopersicum LA4504 and S. pimpinellifolium LA2093 were obtained from the C. M. Rick Tomato Genetics Resource Center and maintained by the Department of Plant Sciences, University of California, Davis, CA 95616, U.S.A. This work was funded by NextGeneration BioGreen 21 Program of Rural Development Administration (PJ013269) and the National Research Foundation of Korea (NRF) grants funded by the Korean government (MSIT) (NRF 2019R1A2C2084705 and 2018R1A5A1023599), Republic of Korea.
\end{abstract}

*The $\boldsymbol{e}$-Xtra logo stands for "electronic extra" and indicates that supplementary materials are published online.

The author(s) declare no conflict of interest.

(i) Copyright (C 2021 The Author(s). This is an open access article distributed under the CC BY 4.0 International license. belongs to the YopJ family of acetyltransferases. Our sequence analysis indicated the presence of partially conserved putative catalytic residues. Interestingly, the conserved amino acid residues in the acetyltransferase catalytic triad are not required for effector-triggered immunity. In addition, we show that RipJ does not autoacetylate its lysine residues. Our study reports the identification of the first $R$. solanacearum avirulence protein that triggers bacterial wilt resistance in tomato. We expect that our discovery of RipJ as an avirulence protein will accelerate the development of bacterial wilt-resistant tomato varieties in the future.

Keywords: avirulence, bacterial wilt resistance, plant immunity, plant-pathogenic bacteria, Ralstonia solanacearum, Solanum pimpinellifolium

Owing to their sessile nature, plants are ubiquitous hosts for a diverse range of phytopathogens. In order to protect themselves, plants have evolved two main layers of immunity comprising receptors localized at either the cell surface or various intracellular compartments (Dodds and Rathjen 2010; Dou and Zhou 2012). The first layer of this surveillance system is patterntriggered immunity (PTI), which is activated by the recognition of microbe-associated molecular patterns by pattern-recognition receptors (Boller and Felix 2009; Jones and Dangl 2006). In order to circumvent PTI and promote virulence, many bacterial pathogens deploy effector molecules into host cells via a type III secretion system (Alfano and Collmer 2004). On the other hand, plants have evolved a second layer of immunity consisting of disease resistance $(\mathrm{R})$ proteins, including nucleotide-binding and leucine-rich repeat (LRR) receptor (NLR) proteins and their associated guardees or decoys (Jones and Dangl 2006). NLR proteins directly or indirectly recognize type III secreted effectors (T3SEs) and activate effector-triggered immunity (ETI) 
(Huang et al. 2019). The T3SEs that are perceived by R proteins and trigger immunity are referred to as avirulence effectors.

Ralstonia solanacearum is a bacterial phytopathogen that causes bacterial wilt disease in many plant species, especially Solanaceae crops such as tomato, potato, pepper, and eggplant, mainly in tropical and subtropical regions (Hayward 1991; Mansfield et al. 2012; Yabuuchi et al. 1995). Due to exceptionally broad host range and high genetic diversity, the $R$. solanacearum species complex (RSSC) has been divided into four phylotypes that reflect geographical origin: phylotype I (Asia), phylotypes IIa and IIb (Americas), phylotype III (Africa), and phylotype IV (Australia and Indonesia) (Fegan and Prior 2005; Wicker et al. 2012).

$R$. solanacearum generally possesses over 70 T3SEs, or "Ralstonia-injected proteins" (Rips). Several $R$. solanacearum T3SEs have been studied in the past for their roles in bacterial virulence during infection of host plants. For example, RipG, belonging to the multigenic GALA effector family, has been shown to interfere with ubiquitin signaling to suppress PTI (Angot et al. 2006; Remigi et al. 2011; Wang et al. 2016). RipAY is known to inhibit PTI by interfering with glutathione production (Fujiwara et al. 2016; Mukaihara et al. 2016; Wei et al. 2017). Several Rips have also been studied for their propensity to confer avirulence. RipP2 (formerly known as PopP2), belonging to the Yersinia outer protein J (YopJ) family of acetyltransferases (Tasset et al. 2010), acetylates the WRKY domain of the NLR protein resistance to $R$. solanacearum 1 (RRS1) and activates immunity in Arabidopsis (Deslandes et al. 2002; Le Roux et al. 2015; Sarris et al. 2015; Williams et al. 2014). RipP1 (formerly PopP1) is another acetyltransferase effector from the YopJ family that induces immunity in species of Petunia (Lavie et al. 2002; Poueymiro et al. 2009). RipB was shown to act as an avirulence effector in Nicotiana benthamiana (Nakano and Mukaihara 2019). Recently, the N. benthamiana NLR recognition of XopQ 1 (Roq1) was shown to recognize RipB and confers bacterial wilt resistance when expressed in tomato (Schultink et al. 2017; Thomas et al. 2020). RipAX2, a zinc-dependent protease, is another avirulence effector potentially recognized by a protein encoded in the EBWR9 (Eggplant bacterial wilt resistance 9) quantitative trait locus (QTL) in eggplant AG91-25 (Nahar et al. 2014; Morel et al. 2018a). Another Ralstonia effector, RipAZ1, has been recently identified to trigger bacterial wilt resistance in Solanum americanum accession SP2273 (Moon et al. 2021). These examples demonstrate the wide variety of contributions to virulence and avirulence of the large effector repertoire of $R$. solanacearum and hints at the future first step at resistance breeding through understanding complexities in effector-host dynamics.

Wild plant species are considered excellent sources of $R$ genes with novel recognition specificities (Henry 2019; Maxted and Kell 2009; Pimentel et al. 1997). Some sources of bacterial wilt resistance have been identified in various tomato species such as S. lycopersicum var. cerasiforme, S. pimpinellifolium, and cultivated tomato S. lycopersicum (Aslam et al. 2017; Yang and Francis 2006). S. pimpinellifolium, considered to be the closest wild relative of cultivated tomato (The 100 Tomato Genome Sequencing Consortium et al. 2014; The Tomato Genome Consortium et al. 2012), harbors economically important traits, including fruit quality (Chen and Foolad 1999; Foolad 2007), abiotic stress tolerance, and disease resistance (Lin et al. 2010; Razali et al. 2018; Villalta et al. 2008). The well-described R protein Pto, which confers resistance to bacterial speck disease caused by Pseudomonas syringae in tomato, has been isolated from S. pimpinellifolium (Pedley and Martin 2003; Thapa et al. 2015). Owing to these characteristics, S. pimpinellifolium has historically been a part of various breeding programs in tomato. One such effort to exploit the genetic variation between
S. pimpinellifolium and S. lycopersicum was made by developing a recombinant inbred line (RIL) population from a cross between S. lycopersicum breeding line NCEBR-1 (LA4504) and S. pimpinellifolium accession LA2093 (Ashrafi et al. 2009). However, despite the amenability of genetic studies in S. pimpinellifolium, no comprehensive investigation of bacterial wilt resistance has been carried out with this species thus far.

In this work, we show that $S$. pimpinellifolium accession LA2093 is resistant to several $R$. solanacearum phylotype I strains. We discovered that a type III effector RipJ from avirulent strains induces bacterial wilt resistance in LA2093. In addition, based on sequence and functional analyses, we demonstrate that some RipJ natural variants have lost their avirulence. Finally, we show that the predicted catalytic residues conserved among the YopJ family of acetyltransferases are not essential for RipJ avirulence in S. pimpinellifolium LA2093.

\section{RESULTS}

\section{S. pimpinellifolium accession LA2093 shows} bacterial wilt resistance.

To identify avirulent strains, we tested virulence of the previously reported phylotype I strains Pe_1, Pe_9, Pe_18, and Pe_39 in S. pimpinellifolium LA2093 and S. lycopersicum LA4504 (Prokchorchik et al. 2020; Segonzac et al. 2017). R. solanacearum strains Pe_1 and Pe_39 caused severe wilt symptom in both Solanum spp. (Fig. 1A). Interestingly, strains Pe_9 and Pe_18 showed significantly reduced virulence in S. pimpinellifolium LA2093 as compared with S. lycopersicum LA4504 (Fig. 1A). Pe_1 and Pe_9 were chosen for further analysis based on the reproducibility of disease assay results. Next, in order to quantify $S$. pimpinellifolium LA2093-specific bacterial wilt resistance to the Pe_9 strain, we monitored the survival rate of infected plants using the Kaplan-Meier survival curves (Fig. 1B). Consistent with disease assay results (Fig. 1A), only the Pe_9 straininfected S. pimpinellifolium LA2093 showed a significantly high survival rate as compared with the other compatible interactions (Fig. 1B). These results suggest that $R$. solanacearum Pe_9 may harbor an avirulence effector that can trigger bacterial wilt resistance in S. pimpinellifolium LA2093. However, strain Pe_9 did not induce a clear hypersensitive response when infiltrated in $S$. pimpinellifolium LA2093 leaves (data not shown).

Recently, the effector repertoires of multiple $R$. solanacearum phylotype I strains, including Pe_1 and Pe_9, were reported (Prokchorchik et al. 2020). In order to shortlist candidate avirulence T3SEs, the effector repertoire of avirulent strain Pe_9 was compared with that of virulent strain Pe_1. The T3SEs RipA1, RipAH, RipAX2, and RipP1 were present in the avirulent strain Pe_9 and absent in the virulent strain Pe_1 (Table 1). In addition, RipJ, RipAF1, RipD, RipB, RipAX1, and RipBA, which showed less than $95 \%$ amino acid sequence identity between the two strains, were also selected for further investigation (Table 1).

\section{RipJ confers $R$. solanacearum avirulence in S. pimpinellifolium LA2093.}

To identify the effector that confers Pe_9 avirulence in LA2093, we introduced each of the avirulence candidate effectors, expressed under the $h r p B$ promoter, into the genome of the virulent strain Pe_1 (Monteiro et al. 2012) (Table 1; Supplementary Fig. S1A; Supplementary Table S3). The genomic integration of effectors in the resulting $R$. solanacearum Pe_1 strain was confirmed using gene-specific PCR (Supplementary Fig. S1B). In disease assays, S. lycopersicum LA4504 was susceptible to all tested transgenic Pe_1 strains, indicating that the genomic integration of effectors did not alter the virulence of Pe_1 (Supplementary Fig. S2A and B). Conversely, S. pimpinellifolium 
LA2093 developed significantly reduced wilt symptom after infection with $\mathrm{Pe} \_1$ carrying rip $_{\mathrm{Pe} \_9}$, whereas severe disease development was observed following infection with the other Pe_1 strain (Supplementary Fig. S2A). Consistently, Pe_1 carrying ripJ $_{\mathrm{Pe} \_9}$ showed significantly higher survival rates than nine other effector candidates or the empty vector (EV) when infected in S. pimpinellifolium LA2093 (Supplementary Fig. S2B). To test whether recognition of RipJ is affected when expressed under its native promoter, S. pimpinellifolium LA2093 and S. lycopersicum LA4504 plants were infected with the virulent $R$. solanacearum

A

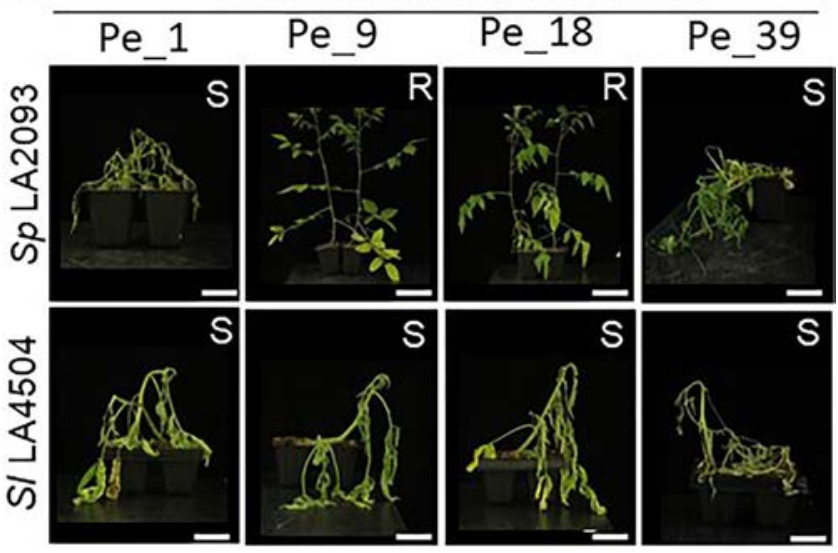

B
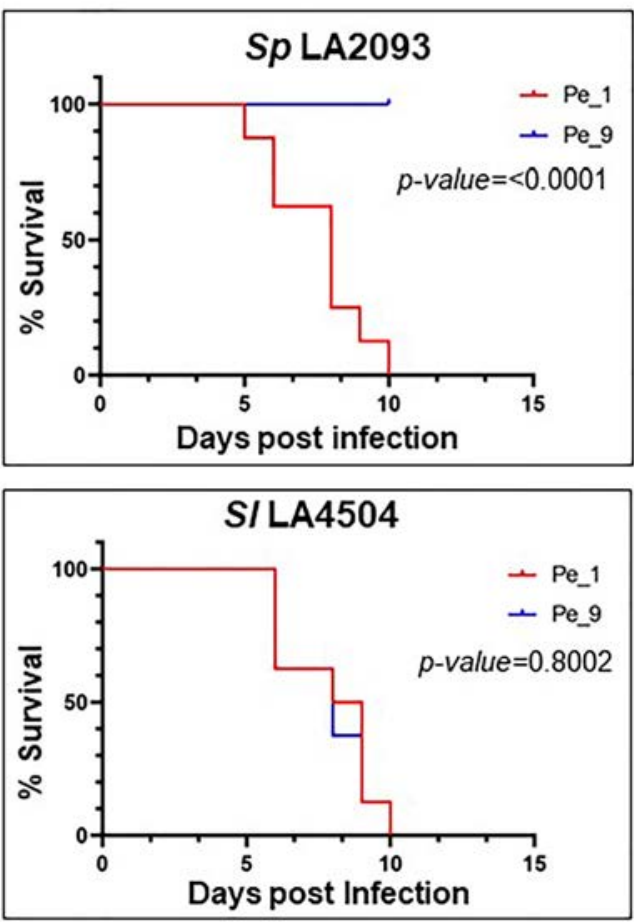

Fig. 1. Ralstonia solanacearum phylotype I strain Pe_9 is avirulent in Solanum pimpinellifolium. A, S. pimpinellifolium accession LA2093 shows bacterial wilt resistance. Four-week-old $S$. pimpinellifolium $(\mathrm{Sp})$ LA2093 and $S$. lycopersicum $(S l)$ LA4504 plants were infected with $R$. solanacearum phylotype I strain Pe_1, Pe_9, Pe_18, and Pe_39 using a soil-drenching method. Representative photographs of infected plants were taken at 10 days postinfection (dpi). S and $\mathrm{R}$ represent susceptibility and resistance, respectively. White scale bars indicate $5 \mathrm{~cm}$. B, S. pimpinellifolium LA2093 plants infected with $R$. solanacearum Pe_9 have a significantly higher survival rate compared with strain Pe_1. Surviving plants were counted for 10 dpi consecutively. The $P$ value indicated in each graph (significant if $P<0.05$ ) was calculated using Mantel-Cox log-rank test comparing curves. strain Pe_1 carrying either rip $J_{\mathrm{Pe} 99}$ whose expression was driven by its native promoter or pRCKgg EV as a control (Supplementary Table S1). As expected, the virulent strain Pe_1 carrying EV or rip $_{\mathrm{Pe} \_} 9$ caused strong bacterial wilt disease in $\bar{S}$. lycopersicum LA4504 (Fig. 2A). Importantly, infection with Pe_1 expressing ripJ $_{\mathrm{Pe} \_9}$ under its native promoter resulted in a strong resistance response in S. pimpinellifolium LA2093 (Fig. 2A; Supplementary Fig. S2A and B). Consistent with disease assays, Pe_1 carrying

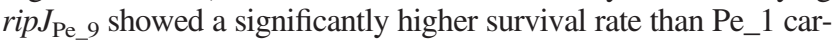
rying EV in S. pimpinellifolium LA2093 but not in S. lycopersicum LA4504 (Fig. 2B). To better characterize the resistance mediated by ripJ $J_{\mathrm{Pe}_{-} 9}$, in planta bacterial growth of Pe_1 carrying $\mathrm{EV}$ or ripJ $J_{\mathrm{Pe} \_9}$ was quantified from the stem of root-infected S. pimpinellifolium LA2093 and S. lycopersicum LA4504 plants at 5 and 10 days postinfection (dpi) (for detailed experimental procedure, see Materials and Methods). Consistent with our survival assay result (Fig. 2B), in planta bacterial growth was significantly restricted only when LA2093 was infected with Pe_1 carrying ripJ $J_{\mathrm{Pe}_{9}}$ (Fig. 2C). Taken together, these results demonstrate that $\mathrm{Rip}_{\mathrm{Je}_{9} 9}$ functions as an avirulence effector in $R$. solanacearum interactions with $S$. pimpinellifolium LA2093.

\section{Some naturally occurring RipJ variants do not confer avirulence.}

Often, natural sequence variation found in avirulence effectors causes loss of recognition (Armstrong et al. 2005; Bos et al. 2006; van Poppel et al. 2008). To investigate the natural variation of RipJ avirulence activity, we first compared the RipJ amino acid sequences from $R$. solanacearum GMI1000 and 30 phylotype I strains that were recently reported (Prokchorchik et al. 2020). Based on amino acid sequence analysis, six representative groups and their representative variants ( $\operatorname{RipJ}_{\mathrm{Pe} \_9}$, $\operatorname{RipJ}_{\mathrm{Pe} 3}$, RipJ $\mathrm{J}_{\mathrm{Pe} 1}, \operatorname{RipJ}_{\mathrm{Pe} \text { 57, }}, \operatorname{RipJ}_{\mathrm{To}}$ 28, and $\operatorname{RipJ}_{\mathrm{GMI} 1000}$ ) were selected for further analysis (Fig. 3A; Supplementary Tables S2 and S3). In comparison with $\mathrm{RipJ}_{\mathrm{Pe} \_9}$ (avirulent variant), $\operatorname{RipJ}_{\mathrm{GMI} 1000}$ and RipJ $\mathrm{Pe} \_3_{3}$ carried only four and one nonsynonymous single-nucleotide polymorphisms, respectively (Fig. 3A; Supplementary Table S2). On the other hand, RipJ $J_{\mathrm{Pe} \_1}$ (virulent variant) and $\mathrm{RipJ}_{\mathrm{Pe} 5} 57$ showed greater polymorphism. In addition, $\operatorname{RipJ}_{\mathrm{To}} 28$ carried 15 unique amino acids at the $\mathrm{C}$ terminus, leading to a stop codon that caused a 51-amino-acid C-terminal truncation compared with $\mathrm{RipJ}_{\mathrm{Pe} \_9}$ (Fig. 3A; Supplementary Table S2).

To test whether these naturally occurring RipJ variations affected avirulence, we introduced representative alleles of these RipJ natural variants expressing under $\mathrm{RipJ}_{\mathrm{Pe} \_9}$ native promoter

Table 1. List of candidate avirulence effectors that induce bacterial wilt resistance in Solanum pimpinellifolium LA2093

\begin{tabular}{lc}
\hline Pe_9 (avirulent) & Pe_1 (virulent) (\%) \\
\hline RipA1 & - \\
RipAH & - \\
RipAX2 & - \\
RipP1 & - \\
RipJ & 94.0 \\
RipAF1 & 94.4 \\
RipD & 91.8 \\
RipB & 85.5 \\
RipAX1 & 70.8 \\
RipBA & 64.1 \\
\hline
\end{tabular}

${ }^{\text {a }}$ Candidate avirulence effectors were selected by comparing the effector repertoires of Ralstonia solanacearum Pe_9 and Pe_1 strains. Effectors that are present in Pe_9 and absent or showing significant polymorphism ( $<95 \%$ amino acid sequence identity) in Pe_1 were selected and indicated in the table; - represents the absence of effectors. Indicated percentages represent amino acid sequence identity between the two effector variants from Pe_9 and Pe_1. 


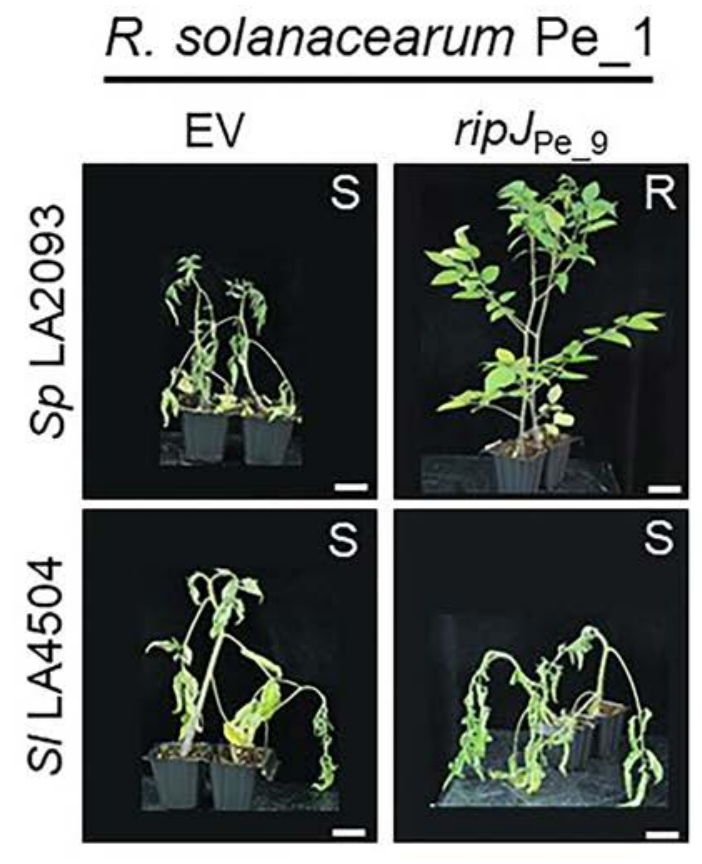

B
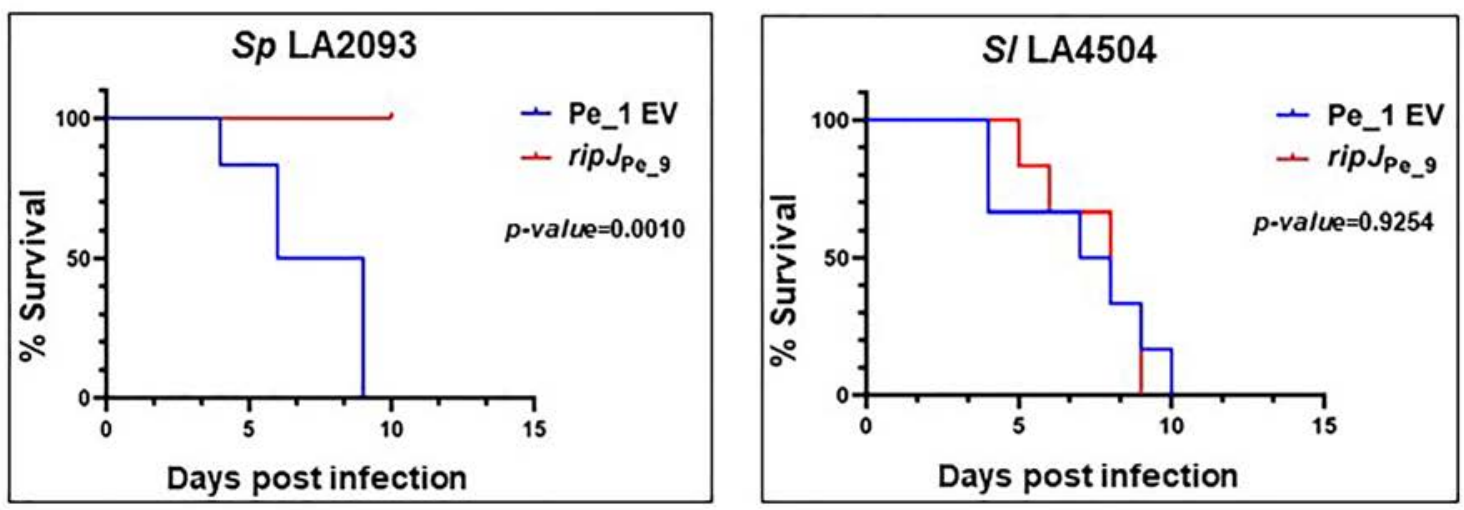

C
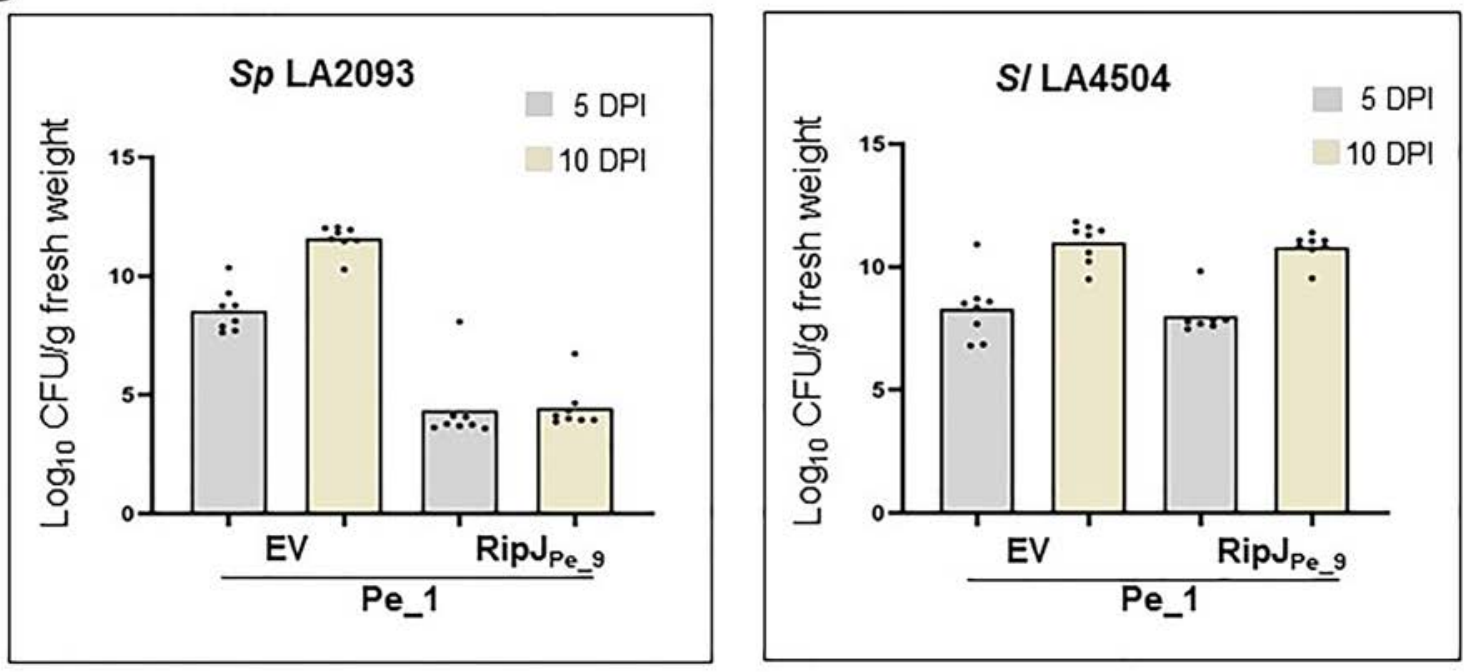

Fig. 2. Introduction of RipJ ${ }_{\mathrm{Pe} \_9}$ in a virulent Ralstonia solanacearum Pe_1 strain confers avirulence in Solanum pimpinellifolium (Sp) LA2093. A, Sp LA2093 but not $S$. lycopersicum $(S l)$ LA4504 shows bacterial wilt resistance to $R$. solanacearum strain Pe_1 carrying ripJ $J_{\mathrm{Pe} \_9}$. Four-week-old plants

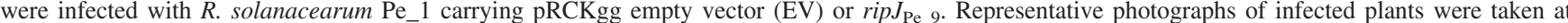
10 days postinfection (dpi). S and R represent susceptibility and resistance, respectively. White scale bars indicate $5 \mathrm{~cm}$. B, S. pimpinellifolium LA2093 plants infected with strain Pe_1 carrying ripJ $J_{\mathrm{Pe}-9}$ display enhanced survival rate. Surviving plants were counted for 10 dpi consecutively. The $P$ value indicated in each graph (significant if $P<0.05$ ) was calculated using a Mantel-Cox log-rank test comparing curves. C, In planta growth of $R$. solanacearum strain Pe_1 carrying EV or ripJ $J_{\mathrm{Pe}_{-} 9}$ inoculated on S. pimpinellifolium LA2093 and S. lycopersicum LA4504 plants at 5 and 10 dpi. Plants were inoculated using a root drenching method $\left(1 \times 10^{8} \mathrm{CFU} / \mathrm{ml}\right)$. Each dot corresponds to the data obtained from a single infected plant. Statistical analyses was performed by one-way analysis of variance with $P$ value $<0.0001$ using Graphpad Prism. 
A

100

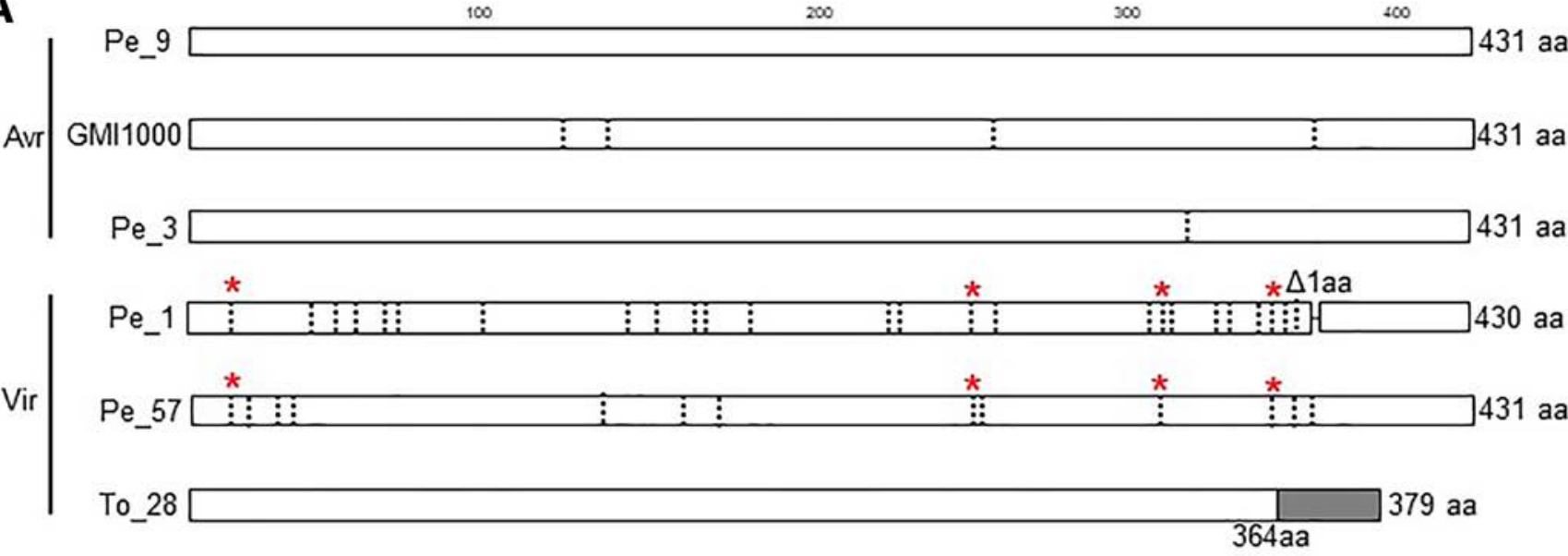

B Pe_1 carrying ripJ natural variant

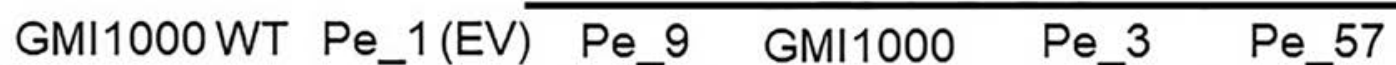
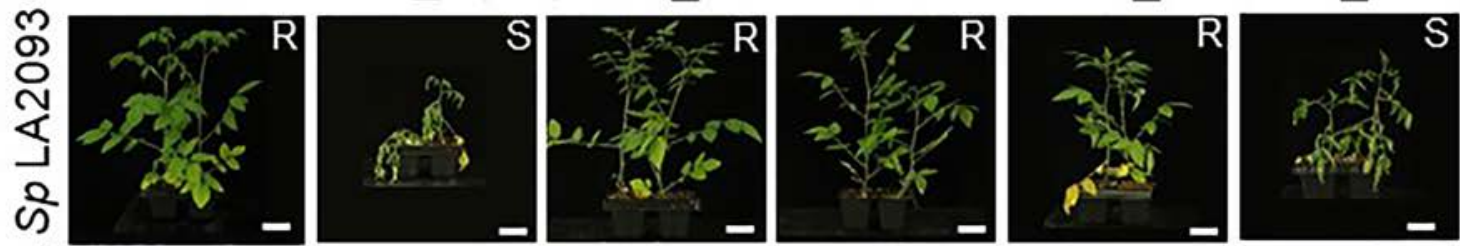

To_28
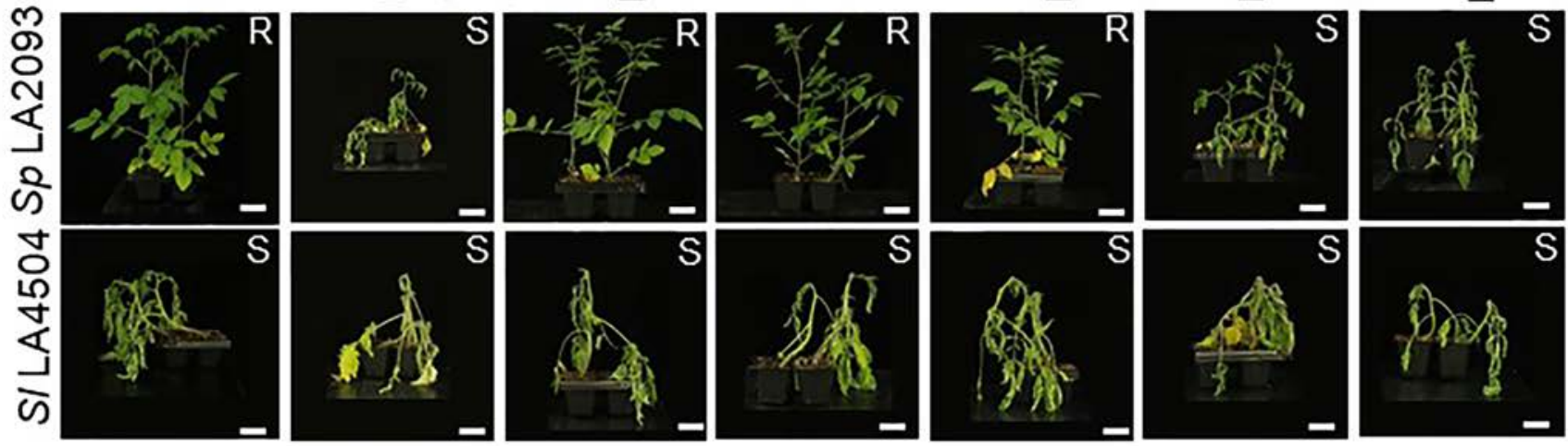

C

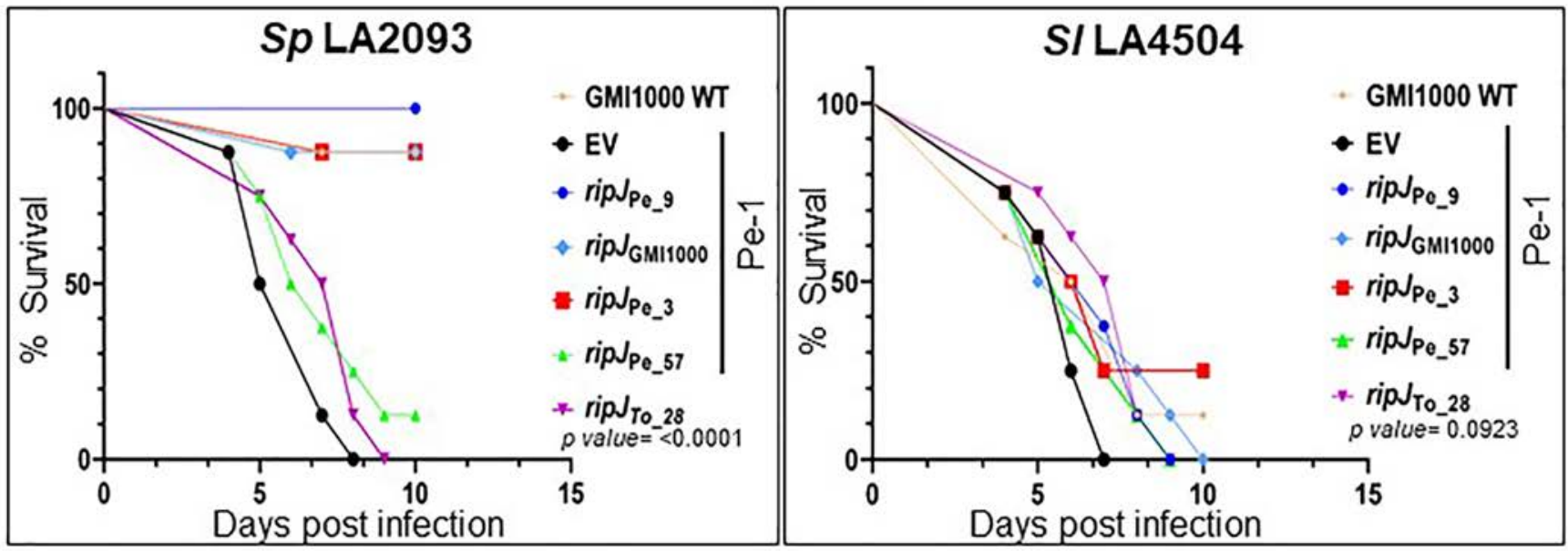

Fig. 3. Some naturally occurring RipJ variants do not confer avirulence. A, Graphical representation of RipJ natural variants from Ralstonia solanacea-

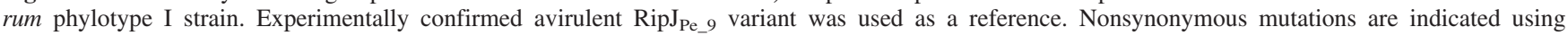
dashed lines. Amino acid residues shared by the virulent variants Pe_1 and Pe 57 are indicated with asterisks. Amino acid sequence changes caused by frameshift mutations are indicated as a gray box. Avr = avirulent, Vir = virulent, and aa = amino acids. B, Several RipJ natural variants have lost avirulence in Solanum pimpinellifolium (Sp) LA2093. Plants were infected with $R$. solanacearum GMI1000 wild-type (WT) and Pe_1 carrying pRCKgg empty vector $(\mathrm{EV})$ or ripJ natural variant. Representative photographs of infected plants were taken at 10 days postinfection (dpi). Sl $=S$. lycopersicum LA4504. S and R represent susceptibility and resistance, respectively. White scale bars indicate $5 \mathrm{~cm}$. C, S. pimpinellifolium LA2093 plants infected with $R$. solanacearum Pe_1 carrying an avirulent ripJ natural variant display an enhanced survival rate. Surviving plants were counted for 10 dpi. The $P$ value indicated in each graph (significant if $P<0.05$ ) was calculated using a Mantel-Cox log-rank test comparing curves. 
in the virulent Pe_1 strain (Fig. 3A; Supplementary Fig. S1A and C). Subsequently, we observed bacterial wilt symptom development in S. lycopersicum LA4504 and S. pimpinellifolium LA2093 infected with the transgenic Pe_1 strains. As expected, strong bacterial wilt disease symptoms were observed in $S$. lycopersicum LA4504 infected with Pe_1 carrying EV or RipJ variants (Fig. 3B). Importantly, the introduction of ripJ $J_{\mathrm{GMI} 1000}$ or ripJ $_{\mathrm{Pe} 3}$ into Pe_1, as seen earlier for ripJ $J_{\mathrm{Pe}-9}$, resulted in bacterial wilt resistance in S. pimpinellifolium LA2093 (Fig. 3B). In contrast, Pe_1 carrying ripJ $J_{\mathrm{Pe} 557}$ or ripJ $J_{\mathrm{To} 28}$ caused strong bacterial wilt symptoms in S. pimpinellifolium LA2093 (Fig. 3B). Consistently, only S. pimpinellifolium LA2093 plants infected with Pe_1 carrying ripJ $J_{\mathrm{GM} 1000}$, ripJ $_{\mathrm{Pe} \_3}$, or ripJ $_{\mathrm{Pe} \_9}$ showed significantly higher survival rates compared with the EV (Fig. 3C). To confirm that the ripJ $J_{\mathrm{Pe}_{-} 1}$ allele does not play a role in avirulence of strain Pe_1 in S. pimpinellifolium LA2093, we generated a virulent $\mathrm{Pe} \_1$ carrying the $\operatorname{rip} J_{\mathrm{Pe} \_1}$ deletion mutant ( $\Delta$ ripJ) (Supplementary Table S3; Supplementary Fig. S3A and B). Furthermore, the transgenic Pe_1 $\Delta$ ripJ strains carrying the ripJ allele from Pe_3, Pe_9, Pe_57, To_28, or GMI1000 were developed. Pe_1 $\Delta$ ripJ showed virulence levels comparable with the Pe_1 wild type infected in S. pimpinellifolium LA2093 (Supplementary Fig. S4A and B). Moreover, the Pe_1 $\Delta$ ripJ strain carrying Pe_3, Pe_9, or GMI1000 allele of ripJ showed an avirulence phenotype, whereas introduction of the Pe_57 or To_28 allele of ripJ did not alter $\mathrm{Pe} \_1 \Delta$ ripJ virulence in $S$. pimpinellifolium LA2093 (Supplementary Fig. S4A and B).

Taken together, these results suggest that Pe_1, Pe_57, and To_28 variants of RipJ have lost their avirulence activity. Interestingly, the sequence polymorphisms V9A, Q274H, M317T, and F363S were commonly found in $\mathrm{RipJ}_{\mathrm{Pe} \_1}$ and $\mathrm{RipJ}_{\mathrm{Pe} \_57}$, suggesting that these mutations might have an important role in evading recognition by the LA2093 immune system (Fig. 3A; Supplementary Table S2).

\section{Mutations in putative acetyltransferase catalytic residues do not alter RipJ avirulence in LA2093.}

Previous studies suggest that RipJ belongs to the YopJ acetyltransferase family (Mukaihara et al. 2010; Peeters et al. 2013). YopJ acetyltransferase family effectors harbor a catalytic triad consisting of histidine, glutamate/aspartate, and cysteine (Ma and $\mathrm{Ma}$ 2016). Protein alignment of $\operatorname{RipJ}_{\mathrm{Pe} 9}$ with the characterized acetyltransferase effectors RipP2, HopZ1, HopZ3, HopZ4, HopZ5, AvrBsT, YopJ, and XopJ revealed that RipJ ${ }_{\mathrm{Pe}, 9}$ harbors only two of the three conserved catalytic residues, histidine 214 and aspartate 235, but not cysteine 287 (Fig. 4A; Supplementary Fig. S6A). The cysteine residue typical of a catalytic triad is substituted by a serine at position 287 in $\mathrm{RipJ}_{\mathrm{Pe} 9}$ (Supplementary Fig. S6B). These residues (H214, D235, and S287) are conserved among all RipJ variants of the six $R$. solanacearum phylotype I strains GMI1000, Pe_9, Pe_3, Pe_1, Pe_57, and To_28 (data not shown).

We hypothesized that $\operatorname{RipJ}_{\mathrm{Pe}-9}$ is an acetyltransferase; mutations in the putative catalytic residues should abolish avirulence in S. pimpinellifolium LA2093. To determine the role of the conserved key residues $\mathrm{H} 214$ and D235 in avirulence, we generated two RipJ $J_{\mathrm{Pe}} 9$ catalytic mutants $(\mathrm{H} 214 \mathrm{~A}$ or D235A) and introduced these mutants into the Pe_1 strain (Supplementary Table S3; Supplementary Fig. S1A and D). Subsequently, S. pimpinellifolium LA2093 and S. lycopersicum LA4504 were infected with $\mathrm{Pe} \_1$ carrying $\mathrm{EV}$, ripJ $J_{\mathrm{Pe}-9}$, or the two ripJ $J_{\mathrm{Pe} \text { 9 }}$ catalytic mutants. As expected, S. lycopersicum LA4504 developed strong bacterial wilt symptoms against all of the strains tested (Fig. 4A). Notably, strain Pe_1 carrying either of the RipJ catalytic mutants $\mathrm{H} 214 \mathrm{~A}$ or D235A caused symptoms and survival rates comparable with wild-type $\mathrm{RipJ}_{\mathrm{Pe} 9}$ in S. pimpinellifolium LA2093 (Fig. 4B and C). To rule out the possibility of a native rip $J_{\mathrm{Pe} \_1}$ allele complementing the catalytic variants $\mathrm{H} 214 \mathrm{~A}$ and $\mathrm{D} 235 \mathrm{~A}$ in trans, we generated the $\operatorname{rip} J_{\mathrm{Pe}_{-} 1}$ deletion mutant in the Pe_1 virulent strain and complemented it with catalytic variants H214A or D235A. Infection assays were performed and survival

A

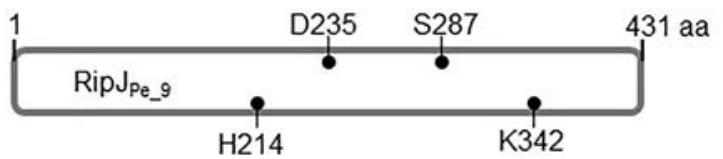

B
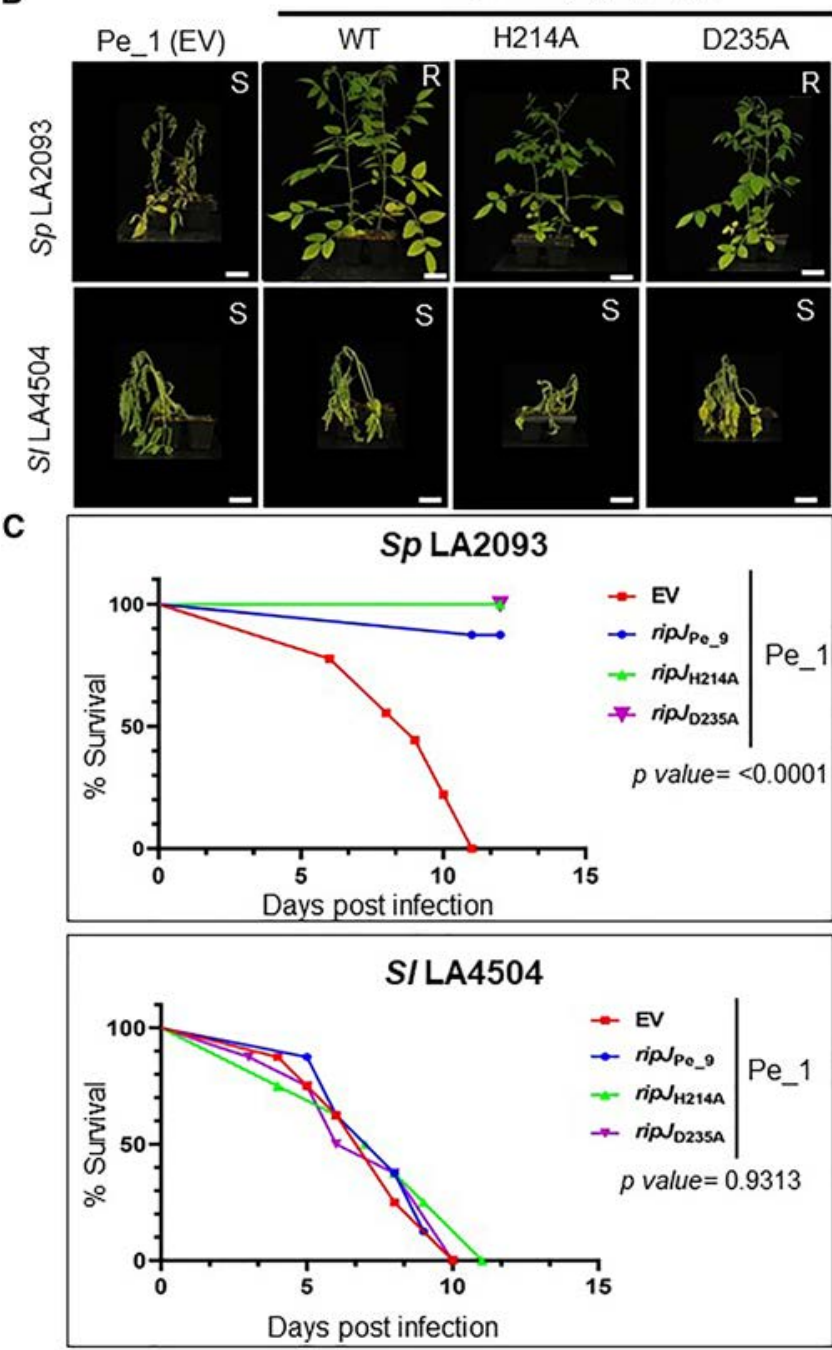

Fig. 4. Mutations in predicted acetyltransferase catalytic residues do not alter RipJ avirulence. A, Schematic representation of key residues of

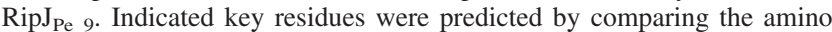
acid (aa) sequences of RipJ $J_{\mathrm{Pe}_{9}}$ and other YopJ family effectors shown in Supplementary Figure S3. Indicated amino acid residues are conserved in Ralstonia solanacearum GMI1000 and all phylotype I strains available in Prokchorchik et al. (2020). Among the predicted acetyltransferase catalytic triad residues, H214 and D235 but not S287 are conserved among YopJ family effectors. K342 indicates the predicted autoacetylation residue. B, Mutations in the conserved catalytic residues do not affect RipJ avirulence. Plants were infected with virulent strain $R$. solanacearum $\mathrm{Pe} \_1$ carrying pRCKgg empty vector $(\mathrm{EV})$, rip $J_{\mathrm{Pe}-9}$ wild-type (WT), or ripJ $J_{\mathrm{Pe} 9}$ catalytic mutants $\mathrm{H} 214 \mathrm{~A}$ and D235A. $S p=$ Solanum pimpinellifolium LA2093 and $S l=S$. lycopersicum LA4504. Representative photographs of infected plants were taken at 10 days postinfection (dpi). S and $\mathrm{R}$ represent susceptibility and resistance, respectively. White scale bars indicate $5 \mathrm{~cm}$. C, Mutations in conserved catalytic residues do not affect RipJ-triggered immunity. Plant infection was performed as described in B. Surviving plants were counted for 10 dpi. The $P$ value indicated in each graph (significant if $P<0.05$ ) was calculated using Mantel-Cox log-rank test comparing curves. 
rates were quantified. Results indicate that Pe_1 $\Delta$ ripJ strains complemented with catalytic variants $\mathrm{H} 214 \mathrm{~A}$ or D235A maintain their avirulence phenotype in S. pimpinellifolium LA2093 whereas they continue to cause strong bacterial wilting in S. lycopersicum LA4504 (Supplementary Fig. S5A and B). Together, these results indicate that mutations in the putative acetyltransferase catalytic residues do not abolish the avirulence of RipJ.

Autoacetylation of the conserved lysine residue in HopZ5, RipP2, or HopZ1a was shown to be required for avirulence (Jayaraman et al. 2017; Lee et al. 2012; Mukaihara et al. 2010). Our alignment result indicated that this lysine residue (K342) is present in $\mathrm{RipJ}_{\mathrm{Pe} \_9}$ (Fig. 4A; Supplementary Fig. S6C). We hypothesized that RipJ might also be autoacetylated if it carries acetyltransferase activity. To test this, we expressed two natural variants of $\operatorname{RipJ}\left(\operatorname{RipJ}_{\mathrm{Pe}_{9} 9}\right.$ and $\left.\mathrm{RipJ}_{\mathrm{Pe}_{2} 1}\right)$ in $N$. benthamiana leaf cells by Agrobacterium-mediated transient transformation. The wild type and C218A mutant of HopZ5 were used as positive and negative controls, respectively (Jayaraman et al. 2017). Immunoblot analysis with anti-AcK antibody suggested that neither $\mathrm{RipJ}_{\mathrm{Pe} \_9}$ nor $\mathrm{RipJ}_{\mathrm{Pe} \_1}$ is acetylated on lysine residues (Fig. 5). However, we cannot exclude the possibility that a serine or threonine residue of RipJ is acetylated.

\section{DISCUSSION}

RipJ has previously been predicted to belong to the YopJ family of acetyltransferases (Ma and Ma 2016; Mukaihara et al. 2010; Peeters et al. 2013). Here, we report that RipJ acts as an avirulence effector in S. pimpinellifolium accession LA2093. We further show that some naturally occurring RipJ variants do not induce bacterial wilt resistance in LA2093. Interestingly, the conserved acetyltransferase catalytic residues of RipJ are not required for avirulence.

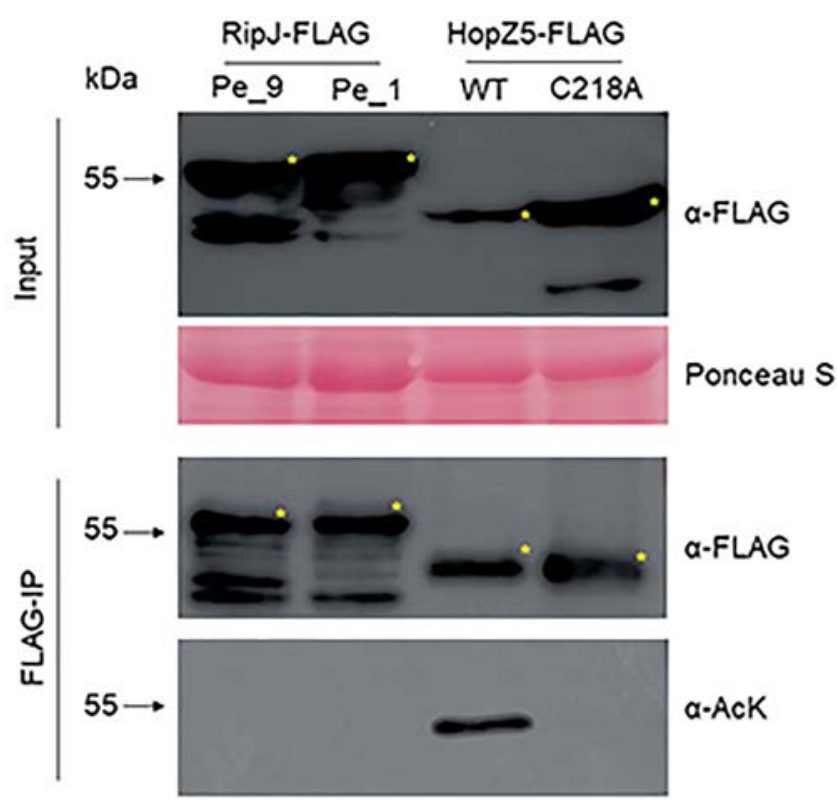

Fig. 5. RipJ does not autoacetylate lysine residues. HopZ5 wild-type (WT) and acetyltransferase catalytic mutant C218A were used as positive and negative controls, respectively. The C-terminally FLAG-tagged RipJ or HopZ5 variants were expressed in Nicotiana benthamiana leaf cells using Agrobacterium-mediated transient transformation. Total proteins were extracted from the infiltrated leaves at 2 days postinfection (dpi) and detected with antiacetyl lysine antibody $(\alpha-A c K)$ after immunoprecipitation with anti-FLAG antibody ( $\alpha$-FLAG). Ponceau staining shows the Rubisco band as a measure of similar loading of total protein. Protein bands of expected sizes are indicated with yellow asterisks.

\section{S. pimpinellifolium LA2093 is a new source of bacterial} wilt resistant tomato breeding.

Two major QTLs, Bacterial wilt resistance locus-12 (Bwr-12) and $B w r-6$, were shown to be associated with bacterial wilt resistance in S. lycopersicum 'Hawaii 7996' (Carmeille et al. 2006; Wang et al. 2000). Recently, it was shown that Bwr-12 harbors the genes encoding LRR receptor-like proteins (Kim et al. 2018). Several $R$. solanacearum T3SEs such as RipAX2, RipP1, RipP2, RipN, and RipS5 were predicted to be associated with avirulence in Hawaii 7996 (Pensec et al. 2015). However, the avirulence effector that is recognized in Hawaii 7996 is unknown. Several wild tomato species have been extensively used to introduce beneficial traits; in particular, disease resistance to crops. Large-scale screens in multiple Solanum spp. showed that three $S$. lycopersicum and one $S$. peruvianum accessions are resistant to $R$. solanacearum (Kim et al. 2016). Interestingly, this study did not identify $S$. pimpinellifolium as a resistance source. As demonstrated in our study, some natural variants of RipJ do not confer avirulence. Therefore, it is plausible that $R$. solanacearum strain WR-1 used by Kim et al. (2016) did not carry an avirulent allele of RipJ.

S. pimpinellifolium is the closest relative of cultivated tomato varieties and a source of important traits such as disease resistance (Miller and Tanksley 1990). Owing to several desirable traits, a high-quality genome sequence of $S$. pimpinellifolium accession LA2093 was recently assembled (Wang et al. 2020). Moreover, a genotyping-by-sequencing-based high-resolution genetic map of the RIL population constructed from a cross between S. pimpinellifolium LA2093 and S. lycopersicum LA4504 has been developed (Gonda et al. 2019). Analysis of this RIL population for RipJ-triggered bacterial wilt resistance may help accelerate the identification of corresponding disease resistance genes. Based on the sequence analysis of currently available $R$. solanacearum genomes, the corresponding $R$ gene for RipJ may provide disease resistance to approximately $50 \%$ of the RSSC. According to the RalstoT3E database, RipJ is mostly present in $R$. solanacearum phylotype I, IIa, and IIb strains but absent in phylotype III and IV strains. Thus, if the corresponding $R$ gene is identified, it may be a valuable source to develop bacterial wilt-resistant tomato varieties against phylotype I and II strains. However, we cannot exclude the possibility that RipJ is present in phylotype III and IV strains, whose genome sequences are not available.

\section{Identification of RipJ as a unique member of the YopJ type III effector family.}

The YopJ family is a unique T3SE family found in both animal and plant pathogens (Ma and Ma 2016). Previous phylogenetic analysis have predicted RipJ as a group V effector of the AvrRxv/YopJ superfamily, along with RipP2 and RipAE (Ma and Ma 2016). YopJ family effectors share an evolutionarily conserved His/Glu/Cys or His/Asp/Cys catalytic triad (Zhang et al. 2016). The catalytic triad is essential for enzymatic activity and virulence of YopJ effectors (Üstün and Bornke 2015; Üstün et al. 2013). Studies on avirulence of the YopJ effector family members revealed that the catalytic triad and its corresponding function are important for perception by host plant $\mathrm{R}$ proteins (Orth et al. 2000; Roden et al. 2004; Whalen et al. 2008). In this study, we identified RipJ as a unique member of the YopJ family because it only has two of the conserved catalytic triad residues (i.e., H214 and D235). Serine (S287) is conserved in RipJ in the same position where the cysteine of the triad was expected. Moreover, unlike other YopJ family effectors identified to date, mutations in the RipJ catalytic triad do not alter avirulence. However, the contribution of the S287 residue to avirulence requires further investigation (Ma et al. 2015). 
Often, autoacetylation of YopJ family effectors is required for in planta function. For instance, HopZ5, a T3SE of $P$. syringae pv. actinidiae, autoacetylates a lysine residue (K278) to trigger defense in Arabidopsis and Nicotiana spp. (Jayaraman et al. 2017). In addition, $R$. solanacearum effector RipP2 also autoacetylates a lysine residue (K383) for activation of RRS1mediated immunity (Tasset et al. 2010). Therefore, it is surprising that the RipJ autoacetylation at the conserved lysine residue (K342) was undetected in our study. However, we cannot exclude the possibility that RipJ autoacetylates serine or threonine residues. Alternatively, the presence of an unknown cofactor that is absent in $N$. benthamiana might be required for RipJ acetyltransferase activity. Further biochemical experiments seem to be necessary to better understand RipJ function in the future. In addition, identification of an in planta target protein would be required to reveal the biochemical activity of RipJ in the future.

\section{MATERIALS AND METHODS}

\section{Plant material and growth conditions.}

Tomato germplasms of two accessions, S. pimpinellifolium LA2093 and S. lycopersicum LA4504 (NCEBR-1), were obtained from the C. M. Rick Tomato Genetics Resource Center. Seed were soaked in water and incubated at $28^{\circ} \mathrm{C}$ for 5 days in darkness to induce germination. Seedlings were transplanted in soil 2 to 3 days after germination. Plants were grown in a growth chamber at $24^{\circ} \mathrm{C}$ with a photoperiod of $16 \mathrm{~h}$ of light and $8 \mathrm{~h}$ of darkness.

\section{Bacterial strains and culture condition.}

$R$. solanacearum strains Pe_1 and Pe_9, described by Prokchorchik et al. (2020) and Segonzac et al. (2017), were isolated from pepper or tomato hosts in various geographical regions of South Korea. Wild-type and modified strains were cultured in liquid BG medium (1\% Bacto peptone, $0.1 \%$ yeast extract, and $0.1 \%$ casamino acid) containing appropriate antibiotics when required and were grown at $28^{\circ} \mathrm{C}$ with shaking at $150 \mathrm{rpm}$ overnight. For pathogenicity assays, cells were incubated at $28^{\circ} \mathrm{C}$ for $48 \mathrm{~h}$ on $\mathrm{BG}$ complete medium supplemented with $1.5 \%$ Bacto agar, $0.5 \%$ glucose, $0.005 \%$ triphenyl tetrazolium chloride (TTC), and relevant antibiotics.

\section{Pathogenicity assays and statistical analysis.}

$S$. pimpinellifolium and S. lycopersicum plants were grown for 4 weeks in a controlled room at $24^{\circ} \mathrm{C}$ with a photoperiod of 16 $\mathrm{h}$ of light and $8 \mathrm{~h}$ of darkness, before infection. $R$. solanacearum cells were cultured and resuspended in $10 \mathrm{mM} \mathrm{MgCl} 2$. The bacterial suspension was adjusted to an optical density at $600 \mathrm{~nm}$ absorbance $\left(\mathrm{OD}_{600}\right)$ of 0.1 (approximately $\left.10^{8} \mathrm{CFU} / \mathrm{ml}\right)$ with 10 $\mathrm{mM} \mathrm{MgCl}$. Plant roots were cut by passing a blade through the soil in a circle with a $1-\mathrm{cm}$ distance from the stem and $15 \mathrm{ml}$ of the bacterial suspension was poured onto the soil. Bacterial wilt symptoms were scored 10 to 12 dpi. Eight plants per accession were tested for each $R$. solanacearum strain. The severity of the wilting symptoms was quantified daily and its rate was plotted with Kaplan-Meier survival curves by using GraphPad Prism version 8.4.3 (GraphPad Software, San Diego, CA, U.S.A.). The $\log$ rank Mantel-Cox method was used to compute the $P$ value of the survival distribution (Morel et al. 2018a). For bacterial load quantification in the stem, $1 \mathrm{~cm}$ of the stem just above the cotyledon was sampled, weighed, and surface sterilized with $70 \%$ ethanol solution. The sample was sectioned into six parts and immersed in $1 \mathrm{ml}$ of sterile water for a minimum of $30 \mathrm{~min}$ for bacteria to ooze out of the stem. Appropriate dilutions were plated and the bacterial load was quantified as described by Morel et al. (2018b). Experiments were conducted three times with similar results.

\section{Type III effector cloning.}

Candidate avirulence effectors (Table 1) were first cloned in pICH41021 (a modified pUC19 shuttle vector, wherein the BsaI site has been removed via mutagenesis). ripA1, ripAH, ripAX2, ripP1, and ripAF1 were cloned from $R$. solanacearum genomic DNA. $R$. solanacearum genomic DNA was isolated using the Wizard Genomic DNA Purification Kit (Promega Corp., Madison, WI, U.S.A.) as per the manufacturer's protocol. Internal $B s a \mathrm{I}$ sites in the cloned effector sequences were eliminated through site-directed mutagenesis. $\operatorname{ripJ}, \operatorname{ripD}, \operatorname{rip} B, \operatorname{rip} A X 1$, and ripBA were codon optimized and synthesized by Integrated DNA Technologies (IDT, Coralville, IA, U.S.A.) (sequences available upon request). BsaI and SfiI enzyme sites were eliminated before synthesis to aid in Golden Gate assembly and plasmid linearization, respectively. DNA sequences of the constructs were confirmed by sequencing using the M13F and M13R primer pair, performed by Solgent (Daejon, South Korea) The pRC vector toolkit is a specific delivery system that allows the incorporation of genes or constructs in a permissible site in the $R$. solanacearum genome through double crossover (Monteiro et al. 2012). The pRCK (Monteiro et al. 2012) was modified to generate pRCKgg, which is a Golden-Gate-compatible version, as described by Moon et al. (2021). Effector constructs in pICH41021 were assembled into the destination pRCKgg vector through Golden Gate assembly (Engler et al. 2008), with a $h r p B$ (230 bp) or ripJ $J_{\mathrm{Pe} \_9}$ native promoter $(1,000 \mathrm{bp})$. A residual Shine-Dalgarno sequence AGGAG or GAGG is present at -891 to -867 or -14 to -10 bp from the start codon in $h r p B$ or ripJ, respectively (Supplementary Fig. S7). The final constructs in pRCKgg were confirmed through gene-specific restriction enzyme digestion. For Agrobacterium-mediated delivery, effectors were assembled in pICH86988 binary vector with an appropriate C-terminal epitope tag through Golden Gate assembly. Assembled constructs were selected with appropriate antibiotics of the concerned destination vector. Integration of the constructs was screened with a blue-white screen using $15 \mu \mathrm{l}$ of $100 \mathrm{mM}$ of isopropyl- $\beta$-D-thiogalactoside and $800 \mu \mathrm{g}$ of 5-bromo-4-chloro-3-indolyl- $\beta$-D-galactoside. Correct integration was ultimately confirmed with restriction enzyme digestion. Constructs were transformed into Agrobacterium tumefaciens strain AGL1 through electroporation.

RipJ knockout was constructed as described by $\mathrm{Wu}$ et al. (2018). ripJ knockout plasmid was constructed by amplifying 989 bp of the $5^{\prime}$ sequence of ripJ open reading frame (ORF) and $494 \mathrm{bp}$ consisting of $117 \mathrm{bp}$ of the ripJ ORF sequence and 377 bp of the 3' sequence of ripJ ORF from genomic DNA of $R$. solanacearum Pe_1 (virulent strain) (Supplementary Fig. S3A). BsaI sites were added to $5^{\prime}$ and $3^{\prime}$ ends for cloning in pICH41021. A Spec ${ }^{\mathrm{R}}$ cassette was amplified from pCR8 (Invitrogen) consisting of a BsaI site on both $5^{\prime}$ and $3^{\prime}$ ends and was cloned in pICH40121. Modules were assembled in pRCgg plasmid using BsaI. Ampicillin and spectinomycin were used for selecting the colonies. Assemblies were further verified using restriction enzyme digestion and visualized through agarose gel electrophoresis (Supplementary Fig. S3A and B).

\section{Natural transformation of $\boldsymbol{R}$. solanacearum.}

All candidate avirulence T3SEs cloned in pRCKgg were transformed into $R$. solanacearum strain Pe_1 (Table 1) using a modified protocol (Perrier et al. 2018). A single colony of $R$. solanacearum Pe_1 was cultured in $15 \mathrm{ml}$ of one-fourth strength M63 minimal medium (15 mM ammonium sulfate, $1.8 \mu \mathrm{M}$ iron(II) sulfate, $100 \mathrm{mM}$ monopotassium phosphate, and $1 \mathrm{mM}$ magnesium sulfate heptahydrate adjusted to $\mathrm{pH} 7$ with $\mathrm{KOH}$ ) supplemented with $2 \%$ glycerol and incubated at $28^{\circ} \mathrm{C}$ for approximately $36 \mathrm{~h}$, to reach an $\mathrm{OD}_{600}$ of 0.4 to 0.6. Each T3SE construct (500) was linearized using the SfiI restriction 
enzyme. Linearized plasmid was purified using Sepharose 4B column. Bacterial culture $(100 \mu \mathrm{l})$ was mixed with the linearized DNA. The mixture was spotted on BG complete medium supplemented with TTC and agar and incubated at $28^{\circ} \mathrm{C}$ for $48 \mathrm{~h}$. The grown cells were then harvested in $1 \mathrm{ml}$ of liquid $\mathrm{BG}$ medium and plated onto a new BG agar medium supplied with TTC and kanamycin at $50 \mu \mathrm{g} / \mathrm{ml}$. Plates were incubated at $28^{\circ} \mathrm{C}$ for 48 to $56 \mathrm{~h}$ to allow transformants to appear. Transformed colonies were selected by PCR as described in Supplementary Figure S1.

\section{Agrobacterium-mediated transient transformation.}

Cultured A. tumefaciens AGL1 cells were harvested by centrifugation and resuspended in Agrobacterium infiltration buffer (10 $\mathrm{mM} \mathrm{MgCl} 2$ and $10 \mathrm{mM}$ 2-(N-morphino) ethanesulfonic acid adjusted to $\mathrm{pH} 5.6$ with $\mathrm{KOH}$ ). $\mathrm{OD}_{600}$ of the suspension was adjusted to 0.4. The bacterial suspension was infiltrated into the abaxial side of 4-week-old plant leaves with a blunt-end needleless syringe. Leaf discs were harvested 2 days postinfiltration for immunoblot analysis.

Protein extraction, sodium dodecyl sulfate polyacrylamide gel electrophoresis, and immunoprecipitation.

For immunoprecipitation, agroinfiltrated leaves of $N$. benthamiana expressing the T3SE of interest were ground to a fine powder using liquid nitrogen. The sample was resuspended in extraction buffer (150 mM Tris-HCl [pH 7.5], $150 \mathrm{mM} \mathrm{NaCl}, 1$ mM EDTA, $10 \%$ glycerol, $0.2 \%$ Nonidet P40, 2\% polyvinylpyrollidon, $10 \mathrm{mM}$ dithiothreitol, and one tablet of protease inhibitor cocktail) and centrifuged at 5,000 $\times g$ for $20 \mathrm{~min}$ at $4^{\circ} \mathrm{C}$. The supernatant was filtered and clear lysate was incubated using anti-FLAG beads (Sigma-Aldrich, St. Louis, MO, U.S.A.) for $2 \mathrm{~h}$ at $4^{\circ} \mathrm{C}$. Finally, magnetic beads were washed thrice in extraction buffer and the sample was eluted by boiling the beads in $80 \mu \mathrm{l}$ of $1 \times$ sodium dodecyl sulfate (SDS) sample buffer at $95^{\circ} \mathrm{C}$ for $5 \mathrm{~min}$. Proteins were separated with SDS polyacrylamide gel electrophoresis and were transferred onto a polyvinylidene diflouride membrane using standard protocols of Western blot. Membranes were probed with $\alpha$-FLAG (Sigma-Aldrich) or with antiacetyl-lysine antibody $(\boldsymbol{\alpha}-\mathrm{AcK})$ used at a dilution 1:10,000. Hrp-conjugated antimouse was used at a dilution 1:5,000 as a secondary antibody. Proteins were visualized with SuperSignal West Dura Extended Substrate and SuperSignal West Femto Maximum Sensitivity Substrate (Thermo Scientific, Rockford, IL, U.S.A.) in an ImageQuant LAS 500 Chemiluminescence CCD Camera (GE Healthcare, Chicago, IL, U.S.A.). Visualization of the loaded total protein was achieved through Ponceau S staining.

\section{ACKNOWLEDGMENTS}

We thank H. Cho and Y. K Lee (Rural Development Administration, Republic of Korea) for providing the $R$. solanacearum strains.

\section{AUTHOR-RECOMMENDED INTERNET RESOURCES}

C. M. Rick Tomato Genetics Resource Center: https://tgrc.ucdavis.edu/ RalstoT3E database:

https://iant.toulouse.inra.fr/bacteria/annotation/site/prj/T3Ev3/

\section{LITERATURE CITED}

Alfano, J. R., and Collmer, A. 2004. Type III secretion system effector proteins: Double agents in bacterial disease and plant defense. Annu. Rev. Phytopathol. 42:385-414.

Angot, A., Peeters, N., Lechner, E., Vailleau, F., Baud, C., Gentzbittel, L., Sartorel, E., Genschik, P., Boucher, C., and Genin, S. 2006. Ralstonia solanacearum requires F-box-like domain-containing type III effectors to promote disease on several host plants. Proc. Natl. Acad. Sci. U.S.A. 103:14620-14625.

Armstrong, M. R., Whisson, S. C., Pritchard, L., Bos, J. I., Venter, E., Avrova, A. O., Rehmany, A. P., Bohme, U., Brooks, K., Cherevach, I., Hamlin, N., White, B., Fraser, A., Lord, A., Quail, M. A., Churcher, C., Hall, N., Berriman, M., Huang, S., Kamoun, S., Beynon, J. L., and Birch, P. R. 2005. An ancestral oomycete locus contains late blight avirulence gene Avr3a, encoding a protein that is recognized in the host cytoplasm. Proc. Natl. Acad. Sci. U.S.A. 102:7766-7771.

Ashrafi, H., Kinkade, M., and Foolad, M. R. 2009. A new genetic linkage map of tomato based on a Solanum lycopersicum $\times S$. pimpinellifolium RIL population displaying locations of candidate pathogen response genes. Genome 52:935-956.

Aslam, M. N., Mukhtar, T., Hussain, M. A., and Raheel, M. 2017. Assessment of resistance to bacterial wilt incited by Ralstonia solanacearum in tomato germplasm. J. Plant Dis. Prot. 124:585-590.

Boller, T., and Felix, G. 2009. A renaissance of elicitors: Perception of microbe-associated molecular pattens and danger signals by patternrecognition receptors. Annu. Rev. Plant Biol. 60:379-406.

Bos, J. I., Kanneganti, T. D., Young, C., Cakir, C., Huitema, E., Win, J. Armstrong, M. R., Birch, P. R., and Kamoun, S. 2006. The C-terminal half of Phytophthora infestans RXLR effector AVR3a is sufficient to trigger R3a-mediated hypersensitivity and suppress INF1-induced cell death in Nicotiana benthamiana. Plant J. 48:165-176.

Carmeille, A., Caranta, C., Dintinger, J., Prior, P., Luisetti, J., and Besse, P. 2006. Identification of QTLs for Ralstonia solanacearum race 3-phylotype II resistance in tomato. Theor. Appl. Genet. 113:110-121.

Chen, F. Q., and Foolad, M. R. 1999. A molecular linkage map of tomato based on a cross between Lycopersicon esculentum and L. pimpinellifolium and its comparison with other molecular maps of tomato. Genome 42:94-103.

Deslandes, L., Olivier, J., Theulieres, F., Hirsch, J., Feng, D. X., BittnerEddy, P., Beynon, J., and Marco, Y. 2002. Resistance to Ralstonia solanacearum in Arabidopsis thaliana is conferred by the recessive RRS1-R gene, a member of a novel family of resistance genes. Proc. Natl. Acad. Sci. U.S.A. 99:2404-2409.

Dodds, P. N., and Rathjen, J. P. 2010. Plant immunity: Towards an integrated view of plant-pathogen interactions. Nat. Rev. Genet. 11:539548.

Dou, D., and Zhou, J. M. 2012. Phytopathogen effectors subverting host immunity: Different foes, similar battleground. Cell Host Microbe 12:484-495.

Engler, C., Kandzia, R., and Marillonnet, S. 2008. A one pot, one step, precision cloning method with high throughput capability. PLoS One 3:e3647.

Fegan, M., and Prior, P. 2005. How complex is the Ralstonia solanacearum species complex. Pages 449-461 in: Bacterial Wilt Disease and the Ralstonia solanacearum Species Complex. C. Allen, P. Prior, and A. C. Hayward, eds. American Phytopathological Society, St. Paul, MN, U.S.A.

Foolad, M. R. 2007. Genome mapping and molecular breeding of tomato Int. J. Plant Genomics 2007:064358.

Fujiwara, S., Kawazoe, T., Ohnishi, K., Kitagawa, T., Popa, C., Valls, M., Genin, S., Nakamura, K., Kuramitsu, Y., Tanaka, N., and Tabuchi, M. 2016. RipAY, a plant pathogen effector protein, exhibits robust gamma-glutamyl cyclotransferase activity when stimulated by eukaryotic thioredoxins. J. Biol. Chem. 291:6813-6830.

Gonda, I., Ashrafi, H., Lyon, D. A., Strickler, S. R., Hulse-Kemp, A. M. Ma, Q., Sun, H., Stoffel, K., Powell, A. F., Futrell, S., Thannhauser, T. W., Fei, Z., Van Deynze, A. E., Mueller, L. A., Giovannoni, J. J., and Foolad, M. R. 2019. Sequencing-based bin map construction of a tomato mapping population, facilitating high-resolution quantitative trait loci detection. Plant Genome 12:180010.

Hayward, A. C. 1991. Biology and epidemiology of bacterial wilt caused by Pseudomonas solanacearum. Annu. Rev. Phytopathol. 29:65-87.

Henry, R. J. 2019. Australian wild rice populations: A key resource for global food security. Front. Plant Sci. 10:1354.

Huang, J., Chen, L., Lu, X., Peng, Q., Zhang, Y., Yang, J., Zhang, B. Y., Yang, B., Waletich, J. R., Yin, W., Zheng, X., Wang, Y., and Dong, S. 2019. Natural allelic variations provide insights into host adaptation of Phytophthora avirulence effector PsAvr3c. New Phytol. 221:10101022.

Jayaraman, J., Choi, S., Prokchorchik, M., Choi, D. S., Spiandore, A., Rikkerink, E. H., Templeton, M. D., Segonzac, C., and Sohn, K. H 2017. A bacterial acetyltransferase triggers immunity in Arabidopsis thaliana independent of hypersensitive response. Sci. Rep. 7:3557.

Jones, J. D. G., and Dangl, J. L. 2006. The plant immune system. Nature 444:323-329 
Kim, B., Hwang, I. S., Lee, H. J., Lee, J. M., Seo, E., Choi, D., and Oh, C. S. 2018. Identification of a molecular marker tightly linked to bacterial wilt resistance in tomato by genome-wide SNP analysis. Theor. Appl. Genet. 131:1017-1030.

Kim, S. G., Hur, O. S., Ro, N. Y., Ko, H. C., Rhee, J. H., Sung, J. S., Ryu, K. Y., Lee, S. Y., and Baek, H. J. 2016. Evaluation of resistance to Ralstonia solanacearum in tomato genetic resources at seedling stage. Plant Pathol. J. 32:58-64.

Lavie, M., Shillington, E., Eguiluz, C., Grimsley, N., and Boucher, C. 2002. PopP1, a new member of the YopJ/AvrRxv family of type III effector proteins, acts as a host-specificity factor and modulates aggressiveness of Ralstonia solanacearum. Mol. Plant-Microbe Interact. 15:1058-1068

Le Roux, C., Huet, G., Jauneau, A., Camborde, L., Tremousaygue, D., Kraut, A., Zhou, B., Levaillant, M., Adachi, H., Yoshioka, H. Raffaele, S., Berthome, R., Coute, Y., Parker, J. E., and Deslandes, L. 2015. A receptor pair with an integrated decoy converts pathogen disabling of transcription factors to immunity. Cell 161:1074-1088.

Lee, A. H.-Y., Hurley, B., Felsensteiner, C., Yea, C., Ckurshumova, W., Bartetzko, V., Wang, P. W., Quach, V., Lewis, J. D., Liu, Y. C., Börnke, F., Angers, S., Wilde, A., Guttman, D. S., and Desveaux, D. 2012. A bacterial acetyltransferase destroys plant microtubule networks and blocks secretion. PLoS Pathog. 8:e1002523.

Lin, K.-H., Yeh, W.-L., Chen, H.-M., and Lo, H.-F. 2010. Quantitative trait loci influencing fruit-related characteristics of tomato grown in high-temperature conditions. Euphytica 174:119-135.

Ma, K.-W., Jiang, S., Hawara, E., Lee, D., Pan, S., Coaker, G., Song, J., and Ma, W. 2015. Two serine residues in Pseudomonas syringae effector HopZ1a are required for acetyltransferase activity and association with the host co-factor. New Phytol. 208:1157-1168.

Ma, K. W., and Ma, W. 2016. YopJ family effectors promote bacterial infection through a unique acetyltransferase activity. Microbiol. Mol. Biol. Rev. 80:1011-1027.

Mansfield, J., Genin, S., Magori, S., Citovsky, V., Sriariyanum, M., Ronald, P., Dow, M., Verdier, V., Beer, S. V., Machado, M. A., Toth, I., Salmond, G., and Foster, G. D. 2012. Top 10 plant pathogenic bacteria in molecular plant pathology. Mol. Plant Pathol. 13:614-629.

Maxted, N., and Kell, S. 2009. Page 266 in: Establishment of a Global Network for the In Situ Conservation of Crop Wild Relatives: Status and Needs. FAO Commission on Genetic Resources for Food and Agriculture, Rome, Italy.

Miller, J. C., and Tanksley, S. D. 1990. RFLP analysis of phylogenetic relationships and genetic variation in the genus Lycopersicon. Theor. Appl. Genet. 80:437-448.

Monteiro, F., Sole, M., van Dijk, I., and Valls, M. 2012. A chromosomal insertion toolbox for promoter probing, mutant complementation, and pathogenicity studies in Ralstonia solanacearum. Mol. Plant-Microbe Interact. 25:557-568.

Moon, H., Pandey, A., Yoon, H., Choi, S., Jeon, H., Prokchorchik, M., Jung, G., Witek, K., Valls, M., McCann, H. C., Kim, M.-S., Jones, J. D. G., Segonzac, C., and Sohn, K. H. 2021. Identification of RipAZ1 as an avirulence determinant of Ralstonia solanacearum in Solanum americanum. Mol. Plant Pathol. 22:317-333.

Morel, A., Guinard, J., Lonjon, F., Sujeeun, L., Barberis, P., Genin, S., Vailleau, F., Daunay, M. C., Dintinger, J., Poussier, S., Peeters, N., and Wicker, E. 2018a. The eggplant AG91-25 recognizes the type IIIsecreted effector RipAX2 to trigger resistance to bacterial wilt (Ralstonia solanacearum species complex). Mol. Plant Pathol. 19:2459-2472.

Morel, A., Peeters, N., Vailleau, F., Barberis, P., Jiang, G., Berthome, R., and Guidot, A. 2018b. Plant pathogenicity phenotyping of Ralstonia solanacearum strains. Pages 223-239 in: Host-Pathogen Interactions. Methods in Molecular Biology, vol. 1734. C. Medina and F. LópezBaena, eds. Humana Press, New York, NY, U.S.A.

Mukaihara, T., Hatanaka, T., Nakano, M., and Oda, K. 2016. Ralstonia solanacearum type III effector RipAY is a glutathione-degrading enzyme that is activated by plant cytosolic thioredoxins and suppresses plant immunity. MBio 7:e00359-16.

Mukaihara, T., Tamura, N., and Iwabuchi, M. 2010. Genome-wide identification of a large repertoire of Ralstonia solanacearum type III effector proteins by a new functional screen. Mol. Plant-Microbe Interact. 23:251-262.

Nahar, K., Matsumoto, I., Taguchi, F., Inagaki, Y., Yamamoto, M., Toyoda, K., Shiraishi, T., Ichinose, Y., and Mukaihara, T. 2014. Ralstonia solanacearum type III secretion system effector Rip36 induces a hypersensitive response in the nonhost wild eggplant Solanum torvum. Mol. Plant Pathol. 15:297-303.

Nakano, M., and Mukaihara, T. 2019. The type III effector RipB from Ralstonia solanacearum RS1000 acts as a major avirulence factor in
Nicotiana benthamiana and other Nicotiana species. Mol. Plant Pathol. 20:1237-1251.

Orth, K., Xu, Z., Mudgett, M. B., Bao, Z. Q., Palmer, L. E., Bliska, J. B., Mangel, W. F., Staskawicz, B., and Dixon, J. E. 2000. Disruption of signaling by Yersinia effector YopJ, a ubiquitin-like protein protease. Science 290:1594-1597.

Pedley, K. F., and Martin, G. B. 2003. Molecular basis of Pto-mediated resistance to bacterial speck disease in tomato. Annu. Rev. Phytopathol. 41:215-243

Peeters, N., Carrere, S., Anisimova, M., Plener, L., Cazale, A. C., and Genin, S. 2013. Repertoire, unified nomenclature and evolution of the Type III effector gene set in the Ralstonia solanacearum species complex. BMC Genomics 14:859.

Pensec, F., Lebeau, A., Daunay, M. C., Chiroleu, F., Guidot, A., and Wicker, E. 2015. Towards the identification of type III effectors associated with Ralstonia solanacearum virulence on tomato and eggplant. Phytopathology 105:1529-1544.

Perrier, A., Barberis, P., and Genin, S. 2018. Introduction of genetic material in Ralstonia solanacearum through natural transformation and conjugation. Pages 201-207 in: Host-Pathogen Interactions. Methods in Molecular Biology, vol. 1734. C. Medina and F. López-Baena, eds. Humana Press, New York, NY, U.S.A.

Pimentel, D., Wilson, C., McCullum, C., Huang, R., Dwen, P., Flack, J., Tran, Q., Saltman, T., and Cliff, B. 1997. Economic and environmental benefits of biodiversity. Bioscience 47:747-757.

Poueymiro, M., Cunnac, S., Barberis, P., Deslandes, L., Peeters, N., Cazale-Noel, A. C., Boucher, C., and Genin, S. 2009. Two type III secretion system effectors from Ralstonia solanacearum GMI1000 determine host-range specificity on tobacco. Mol. Plant-Microbe Interact. 22:538-550.

Prokchorchik, M., Pandey, A., Moon, H., Kim, W., Jeon, H., Jung, G., Jayaraman, J., Poole, S., Segonzac, C., Sohn, K. H., and McCann, H. C. 2020. Host adaptation and microbial competition drive Ralstonia solanacearum phylotype I evolution in the Republic of Korea. Microb. Genomics 2020:6.

Razali, R., Bougouffa, S., Morton, M. J. L., Lightfoot, D. J., Alam, I., Essack, M., Arold, S. T., Kamau, A. A., Schmöckel, S. M., Pailles, Y., Shahid, M., Michell, C. T., Al-Babili, S., Ho, Y. S., Tester, M., Bajic, V. B., and Negrão, S. 2018. The genome sequence of the wild tomato Solanum pimpinellifolium provides insights into salinity tolerance. Front. Plant Sci. 9:1402.

Remigi, P., Anisimova, M., Guidot, A., Genin, S., and Peeters, N. 2011 Functional diversification of the GALA type III effector family contributes to Ralstonia solanacearum adaptation on different plant hosts. New Phytol. 192:976-987.

Roden, J., Eardley, L., Hotson, A., Cao, Y., and Mudgett, M. B. 2004. Characterization of the Xanthomonas AvrXv4 effector, a SUMO protease translocated into plant cells. Mol. Plant-Microbe Interact. 17:633-643.

Sarris, P. F., Duxbury, Z., Huh, S. U., Ma, Y., Segonzac, C., Sklenar, J., Derbyshire, P., Cevik, V., Rallapalli, G., Saucet, S. B., Wirthmueller L., Menke, F. L. H., Sohn, K. H., and Jones, J. D. G. 2015. A plant immune receptor detects pathogen effectors that target WRKY transcription factors. Cell 161:1089-1100.

Schultink, A., Qi, T., Lee, A., Steinbrenner, A. D., and Staskawicz, B. 2017. Roq1 mediates recognition of the Xanthomonas and Pseudomonas effector proteins XopQ and HopQ1. Plant J. 92:787-795.

Segonzac, C., Newman, T. E., Choi, S., Jayaraman, J., Choi, D. S., Jung, G. Y., Cho, H., Lee, Y. K., and Sohn, K. H. 2017. A conserved EAR motif is required for avirulence and stability of the Ralstonia solanacearum effector PopP2 in planta. Front. Plant Sci. 8:1330.

Tasset, C., Bernoux, M., Jauneau, A., Pouzet, C., Briere, C., KiefferJacquinod, S., Rivas, S., Marco, Y., and Deslandes, L. 2010. Autoacetylation of the Ralstonia solanacearum effector PopP2 targets a lysine residue essential for RRS1-R-mediated immunity in Arabidopsis. PLoS Pathog. 6:e1001202.

Thapa, S. P., Miyao, E. M., Michael Davis, R., and Coaker, G. 2015. Identification of QTLs controlling resistance to Pseudomonas syringae pv. tomato race 1 strains from the wild tomato, Solanum habrochaites LA1777. Theor. Appl. Genet. 128:681-692.

The 100 Tomato Genome Sequencing Consortium, Aflitos, S., Schijlen, E., de Jong, H., de Ridder, D., Smit, S., Finkers, R., Wang, J., Zhang, G., Li, N., Mao, L., Bakker, F., Dirks, R., Breit, T., Gravendeel, B., Huits, H., Struss, D., Swanson-Wagner, R., van Leeuwen, H., van Ham, R. C. H. J., Fito, L., Guignier, L., Sevilla, M., Ellul, P., Ganko, E., Kapur, A., Reclus, E., de Geus, B., van de Geest, H., te Lintel Hekkert, B., van Haarst, J., Smits, L., Koops, A., Sanchez-Perez, G., van Heusden, A. W., Visser, R., Quan, Z., Min, J., Liao, L., Wang, X., 
Wang, G., Yue, Z., Yang, X., Xu, N., Schranz, E., Smets, E., Vos, R., Rauwerda, J., Ursem, R., Schuit, C., Kerns, M., van den Berg, J., Vriezen, W., Janssen, A., Datema, E., Jahrman, T., Moquet, F., Bonnet, J., and Peters, S. 2014. Exploring genetic variation in the tomato (Solanum section Lycopersicon) clade by whole-genome sequencing. Plant J. 80:136-148.

The Tomato Genome Consortium. 2012. The tomato genome sequence provides insights into fleshy fruit evolution. Nature 485:635-641.

Thomas, N. C., Hendrich, C. G., Gill, U. S., Allen, C., Hutton, S. F., and Schultink, A. 2020. The immune receptor Roq1 confers resistance to the bacterial pathogens Xanthomonas, Pseudomonas syringae, and Ralstonia in tomato. Front. Plant Sci. 11:463.

Üstün, S., Bartetzko, V., and Bornke, F. 2013. The Xanthomonas campestris type III effector XopJ targets the host cell proteasome to suppress salicylic-acid mediated plant defence. PLoS Pathog. 9: e1003427.

Üstün, S., and Bornke, F. 2015. The Xanthomonas campestris type III effector XopJ proteolytically degrades proteasome subunit RPT6. Plant Physiol. 168:107-119.

van Poppel, P. M., Guo, J., van de Vondervoort, P. J., Jung, M. W., Birch, P. R., Whisson, S. C., and Govers, F. 2008. The Phytophthora infestans avirulence gene Avr4 encodes an RXLR-dEER effector. Mol. Plant-Microbe Interact. 21:1460-1470.

Villalta, I., Reina-Sanchez, A., Bolarin, M. C., Cuartero, J., Belver, A., Venema, K., Carbonell, E. A., and Asins, M. J. 2008. Genetic analysis of $\mathrm{Na}^{+}$and $\mathrm{K}^{+}$concentrations in leaf and stem as physiological components of salt tolerance in tomato. Theor. Appl. Genet. 116:869-880.

Wang, J. F., Olivier, J., Thoquet, P., Mangin, B., Sauviac, L., and Grimsley, N. H. 2000. Resistance of tomato line Hawaii7996 to Ralstonia solanacearum Pss4 in Taiwan is controlled mainly by a major strainspecific locus. Mol. Plant-Microbe Interact. 13:6-13.

Wang, K., Remigi, P., Anisimova, M., Lonjon, F., Kars, I., Kajava, A., Li, C. H., Cheng, C. P., Vailleau, F., Genin, S., and Peeters, N. 2016. Functional assignment to positively selected sites in the core type III effector RipG7 from Ralstonia solanacearum. Mol. Plant Pathol. 17:553-564.

Wang, X., Gao, L., Jiao, C., Stravoravdis, S., Hosmani, P. S., Saha, S., Zhang, J., Mainiero, S., Strickler, S. R., Catala, C., Martin, G. B., Mueller, L. A., Vrebalov, J., Giovannoni, J. J., Wu, S., and Fei, Z.
2020. Genome of Solanum pimpinellifolium provides insights into structural variants during tomato breeding. Nat. Commun. 11:5817.

Wei, Y., Sang, Y., and Macho, A. P. 2017. The Ralstonia solanacearum type III effector RipAY is phosphorylated in plant cells to modulate its enzymatic activity. Front. Plant Sci. 8:1899.

Whalen, M., Richter, T., Zakhareyvich, K., Yoshikawa, M., Al-Azzeh, D., Adefioye, A., Spicer, G., Mendoza, L. L., Morales, C. Q., Klassen, V., Perez-Baron, G., Toebe, C. S., Tzovolous, A., Gerstman, E., Evans, E., Thompson, C., Lopez, M., and Ronald, P. C. 2008. Identification of a host 14-3-3 protein that interacts with Xanthomonas effector AvrRxv. Physiol. Mol. Plant Pathol. 72:46-55.

Wicker, E., Lefeuvre, P., de Cambiaire, J. C., Lemaire, C., Poussier, S., and Prior, P. 2012. Contrasting recombination patterns and demographic histories of the plant pathogen Ralstonia solanacearum inferred from MLSA. ISME J. 6:961-974.

Williams, S. J., Sohn, K. H., Wan, L., Bernoux, M., Sarris, P. F., Segonzac, C., Ve, T., Ma, Y., Saucet, S. B., Ericsson, D. J., Casey, L. W., Lonhienne, T., Winzor, D. J., Zhang, X., Coerdt, A., Parker, J. E., Dodds, P. N., Kobe, B., and Jones, J. D. 2014. Structural basis for assembly and function of a heterodimeric plant immune receptor. Science 344: 299-303.

Wu, D., Schandry, N., and Lahaye, T. 2018. A modular toolbox for Golden-Gate-based plasmid assembly streamlines the generation of Ralstonia solanacearum species complex knockout strains and multicassette complementation constructs. Mol. Plant Pathol. 19:1511-1522.

Yabuuchi, E., Kosako, Y., Yano, I., Hotta, H., and Nishiuchi, Y. 1995 Transfer of two Burkholderia and an Alcaligenes species to Ralstonia gen. nov.: Proposal of Ralstonia pickettii (Ralston, Palleroni and Doudoroff 1973) comb. nov., Ralstonia solanacearum (Smith 1896) comb. nov. and Ralstonia eutropha (Davis 1969) comb. nov. Microbiol. Immunol. 39:897-904.

Yang, W., and Francis, D. M. 2006. Genetics and breeding for resistance to bacterial diseases in tomato: Prospects for marker-assisted selection. Pages 379-419 in: Genetic Improvement of Solanaceous Crops. M. K. Razdan and A. K. Mattoo, eds. CRC Press, Boca Raton, FL, U.S.A.

Zhang, Z. M., Ma, K. W., Yuan, S., Luo, Y., Jiang, S., Hawara, E., Pan, S., Ma, W., and Song, J. 2016. Structure of a pathogen effector reveals the enzymatic mechanism of a novel acetyltransferase family. Nat. Struct. Mol. Biol. 23:847-852. 